\title{
Retention of $\beta$-Carotene in Cream-Fleshed Sweetpotato-Based Complementary Food Stored in Different Containers under Simulated Tropical Temperature and Humidity
}

\author{
Francis Kweku Amagloh ${ }^{1,2}$, Louise Brough ${ }^{2}$, Janet L. Weber ${ }^{2}$, Anthony N. Mutukumira², \\ Allan Hardacre ${ }^{2}$, Jane Coad ${ }^{2 *}$ \\ ${ }^{1}$ Department of Biotechnology (Food Processing Technology Section), Faculty of Agriculture, University for Development Studies, \\ Nyankpala, Ghana; ${ }^{2}$ Institute of Food, Nutrition and Human Health, College of Health, Massey University, Palmerston North, New \\ Zealand. \\ Email: *J.Coad@massey.ac.nz
}

Received June $18^{\text {th }}, 2013$; revised July $18^{\text {th }}, 2013$; accepted July $25^{\text {th }}, 2013$

Copyright (C) 2013 Francis Kweku Amagloh et al. This is an open access article distributed under the Creative Commons Attribution License, which permits unrestricted use, distribution, and reproduction in any medium, provided the original work is properly cited.

\begin{abstract}
The stability of $\beta$-carotene in cream-fleshed sweetpotato-based complementary food stored in three different containers under simulated tropical temperature of $32^{\circ} \mathrm{C}$ and $85 \%$ relative humidity in an environmental chamber for 24 weeks was investigated. The formulation stored in a metallised polyester film in a refrigerator (approximately $3.0^{\circ} \mathrm{C}$ and $95 \%$ relative humidity) retained about $81 \%$ of $\beta$-carotene at 24 weeks, with no significant change in the moisture content. The formulation stored in either a metallised polyester film or a translucent polypropylene container placed in the environmental chamber retained approximately half of the $\beta$-carotene at 24 weeks, with a slight increase in moisture content. However, the formulation held in a transparent low-density polyethylene bag had the lowest $\beta$-carotene retention (37\%) and the highest moisture content at week 24 . Within the limits of this study, it has been demonstrated that $\beta$-carotene in cream-fleshed sweetpotato-based complementary food was well retained when moisture uptake was minimised.
\end{abstract}

Keywords: $\beta$-Carotene; Complementary Food; Storage; Sweetpotato

\section{Introduction}

The vitamin A deficiency among children $<5$ years in sub-Saharan Africa remains high (44\%), second to SouthEast Asia (50\%), compared with the worldwide occurrence of $33 \%$ [1]. The reason could be the widely used cereal-based complementary foods in low-income countries [2], which are naturally low in $\beta$-carotene [3-5]. Therefore, there is the need to find other plant-based complementary food as a source of dietary vitamin A.

Previous publications [5-8] indicate cream-fleshed sweetpotato complementary food, referred to as oventoasted ComFa (a household-level infant food), has several advantages over the commonly used cereal-legume blend (Weanimix). The advantages of the oven-toasted ComFa compared with Weanimix include lower level (230 vs. $800 \mathrm{mg} / 100 \mathrm{~g}$ ) of phytate-an antinutrient that

${ }^{*}$ Corresponding author. inhibits iron, zinc and calcium absorption [6], and high retinol activity equivalents (28.04 vs. $1.52 \mu \mathrm{g}$ retinol activity equivalents $/ 100 \mathrm{kcal}$ ) [5]. Using the phytate: calcium, iron and zinc molar ratios, it was predicted that the sweetpotato-based infant food may limit the absorption of these essential minerals to a less extent than Weanimix [7]. Additionally, the oven-toasted ComFa would potentially avoid excessive energy and nutrient thinning as it would not require excessive dilution with water as would Weanimix during porridge preparation, and also have better desirable sensory characteristics than Weani$\operatorname{mix}[8]$.

In spite of the increasing potential of sweetpotato to contribute to vitamin A status of infants in lower income countries, only a few studies have incorporated sweetpotato as an ingredient in processing dry infant formulations [9-15]. Further, to our knowledge, no study has investigated the stability of $\beta$-carotene in sweetpotato- 
based complementary food. However, the stability of carotenoid in the roots [16,17], chips [18] and flour [19] of sweetpotato has been investigated, it may not be applicable to sweetpotato plus other ingredients matrix.

The stability of $\beta$-carotene in sweetpotato-based complementary food is of nutritional significance if such formulation could be recommended as a dietary source of vitamin A to support on-going vitamin A supplementation programmes in low- and middle-income countries [5, $12,15]$.

This study was conducted to determine the stability of $\beta$-carotene in the oven-toasted ComFa considered in previous studies [5-8] in likely storage containers under a simulated tropical temperature of $32^{\circ} \mathrm{C}$ and $85 \%$ relative humidity.

\section{Materials and Methods}

\subsection{Preparation of the Sweetpotato-Based Complementary Food}

The ingredients and the methods used to prepare the household-level sweetpotato-based complementary food, the oven-toasted ComFa, have been previously described in detail [6]. In brief, a composite flour of $66 \%$ creamfleshed sweetpotato, $10 \%$ full-fat soyabean, $6.0 \%$ soyabean oil, $0.50 \%$ iodised salt, $0.50 \%$ sugar and $17 \%$ fish powder from anchovy, was toasted at $120^{\circ} \mathrm{C}$ for $30 \mathrm{~min}$ utes in a pre-heated oven (AR 85 Electrolux, Steelfort Engineering Company Ltd., Palmerston North, New Zealand). About $500 \mathrm{~g}$ from each of three batches were sampled and put in three different containers.

\subsection{Storage Container}

The three different storage containers used were (Figure 1(a)): a transparent low-density polyethylene bag (LDPE) (UBL ${ }^{\circledR}$, China), a translucent polypropylene container with LDPE snap-on lid (PP) (Huhtamaki Australia, New South Wales, Australia) and a bag made from a roll of metallised polyester film (MPF). A control sample was kept in the metallised polyester film bag and stored in a walk-in refrigerator at $3.0 \pm 1.0^{\circ} \mathrm{C}$ with a relative humidity of $95 \%$ [MPF (control)]. The LDPE and the PP containers are probable household-level storage containers in Ghana (personal observation).

\subsection{Storage Study under Simulated Temperature and Humidity}

An environmental chamber (Figure 1(b)) (Contherm Precision Environmental Chamber, Contherm Scientific Ltd., Lower Hutt, New Zealand) was used in this study. The storage of the sweetpotato-based complementary food was conducted for 24 weeks under a simulated ave-

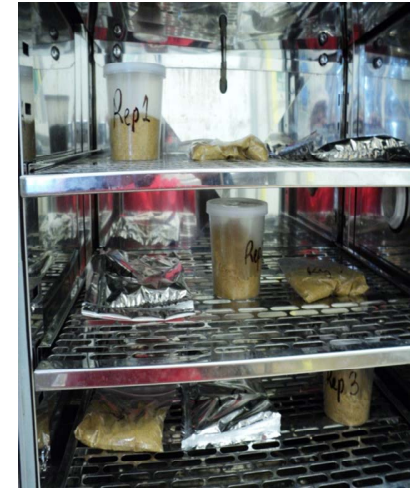

(a)

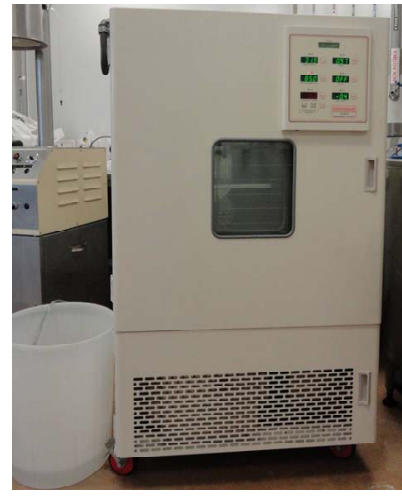

(b)
Figure 1. The three storage containers (a) and Contherm precision environmental chamber (b).

rage temperature of $32^{\circ} \mathrm{C}$ and relative humidity of $85 \%$, mimicking ambient conditions in Ghana, West Africa [20].

\subsection{Sampling}

The sampling points were weeks: 0 (beginning of storage study), 8, 16 and 24. At each sampling point, analytical samples were taken from each container including the control, in triplicate, were mixed by inverting the containers four times and further mixing with the sampling spoon before taking aliquots. About $50 \mathrm{~g}$ from each of the three batches (as replicates) of the formulation stored in the MPF, PP, and LDPE as well as MPF (control) were taken and put into different sample containers. Each sample container was coded with a random 3-digit figure for moisture and $\beta$-carotene analyses. The remaining samples were returned to the environmental chamber or to the walk-in refrigerator, and the sampling described above was repeated at the selected weeks until the end of the study.

\subsection{Moisture Analysis}

About two grams of each of the aliquots sampled were weighed and dried in a forced-air oven (Contherm Oven 240, Contherm Scientific Company Ltd., Lower Hutt, New Zealand) at $108^{\circ} \mathrm{C}$ for approximately 16 hours as previously described [6].

\section{6. $\beta$-Carotene Analysis}

The level of $\beta$-carotene in the blind aliquots (as 3-figure coded samples) of the MPF, PP, LDPE and MPF (control) was determined using the Carr-Price method, AOAC 974.29 (4) by the Nutrition Laboratory, Massey University, New Zealand, using a high performance liquid chromatography (HPLC) (Shimadzu HPLC, Japan). The aliquots were stored in a dark room at about $20^{\circ} \mathrm{C}$, and 
analysed within two weeks of sampling.

For the purpose of quality control, the coded samples were further randomised into four batches by the analyst at the laboratory, and the first sample of each batch was determined in duplicate. The coefficient of variation for the duplicate ranged from 0.47 to $2.3 \%$. Also, a sample void of carotenoids was spiked with $\beta$-carotene (C4582, synthetic crystalline $\geq 95 \%$ HPLC grade, Sigma-Aldrich) and analysed with each of the other three batches. The percentage recovery ranged from $83 \%$ to approximately $100 \%$.

The standard curve generated from $\beta$-carotene (C4582, synthetic crystalline $\geq 95 \%$ HPLC grade, Sigma-Aldrich), which was used to determine the $\beta$-carotene levels, had coefficients of determination ranging from 0.9997 to 0.9999 , indicating an almost perfect linearity.

The $\beta$-carotene values of the samples were corrected for their respective moisture contents.

\subsection{Statistical Analysis}

The data were analysed using the general linear model for repeated measures design in Minitab v15.1 ${ }^{\mathrm{TM}}$ (Minitab Inc., State College, PA, USA) [21]. The betweengroup effect was the storage containers and the withingroup effect was the weeks of sampling. The $\beta$-carotene and moisture values were the response variables. All the predictor variables: storage containers, weeks of sampling, and storage containers $\times$ weeks of sampling, were considered as fixed factors. Statistical significance was set at $\mathrm{P}<0.05$. Tukey's method for pairwise comparison of the least square means [22] was employed for post hoc test when required.

Data were expressed as least square means \pm standard error of means of three independent samples, unless otherwise specified.

\section{Results and Discussion}

\section{1. $\beta$-Carotene Retention}

Data on the loss of $\beta$-carotene in the oven-toasted ComFa, a household-level complementary food, stored in the different containers for 24 weeks are shown in Figure 2.

The MPF (control), the sample in the metallised polyester film stored at $3.0 \pm 1.0^{\circ} \mathrm{C}$ with a relative humidity of $95 \%$, had the highest retention of $\beta$-carotene and was significantly $(\mathrm{P}<0.05)$ higher from weeks 8 to 24 compared with the samples stored in the environmental chamber (Figure 1) at simulated tropical temperature of $32^{\circ} \mathrm{C}$ with $85 \%$ relative humidity. Approximately $81 \%$ of the initial $\beta$-carotene content was retained at the 24 th week in the MPF (control) treatment. The MPF and the $\mathrm{PP}$ stored in the environmental chamber had similar $(\mathrm{P}>$ $0.05)$ retention of $\beta$-carotene. The levels of $\beta$-carotene retention for the formulation in the MPF and the PP containers were respectively: 83 vs. $80 \%$ (week 8), 66 vs. $64 \%$ (week 16) and 60 vs. 49\% (week 24). At week 16, the LDPE treatment level had the highest loss of $\beta$-carotene, approximately $50 \%$ the initial content.

\subsection{Moisture Uptake by the Oven-Toasted ComFa from the Different Containers}

There was no significant change in the moisture content (Figure 3) of the MPF (control) treatment level during the entire storage period of 24 weeks. However, there were approximately 2-, 3- and 6-fold increases in the moisture content of the formulation in the MPF, PP and LDPE containers, respectively. The moisture content was 2-times higher for the formulation stored in the MPF than the sample stored in the MPF (control) suggesting that the constant high temperature of the environmental chamber increased the permeability of the metallised polyester film to moisture.

An expected trend was observed between moisture uptake by the formulations in the different containers and $\beta$-carotene retention. A bivariate correlation between moisture and $\beta$-carotene (expressed on dry matter basis) showed a significant inverse correlation $(\mathrm{P}<0.0001$, Pearson correlation coefficient $=-0.80$ ). Thus, about $64 \%$ of the variability in the $\beta$-carotene levels during storage could be explained by the variation in the moisture content. Therefore, when moisture uptake by sweetpotato-based complementary food is controlled during storage, for example, by keeping the formulation in high-density polyethylene container instead of low-density polyethylene bag; the loss of $\beta$-carotene would be minimal in formulations stored for up to 24 weeks. However, we do not expect such a long storage period for a household-level processed complementary food.

The data suggest that high ambient temperature $\left(32^{\circ} \mathrm{C}\right)$ with high relative humidity $(85 \%)$ could be detrimental to $\beta$-carotene retention during storage. However, a higher relative humidity of $95 \%$ and low temperature ranging between $2.0^{\circ} \mathrm{C}-5.0^{\circ} \mathrm{C}$ do not significantly degrade $\beta$-carotene when stored in a container with good moisture barrier as observed in our control sample [MPF (control)].

Due to the lower level of phytate and higher vitamin A content of the oven-toasted ComFa compared with a maize-based complementary food, we previously suggested that the sweetpotato-based infant food is likely to contribute positively to the nutritional status of infants in lower income countries such as Ghana $[5,6]$, where cereal-only or cereal-legume blends are widely used for complementary feeding [23]. The results of this current study support our suggestion that sweetpotato-based complementary food, when stored appropriately, can be a 


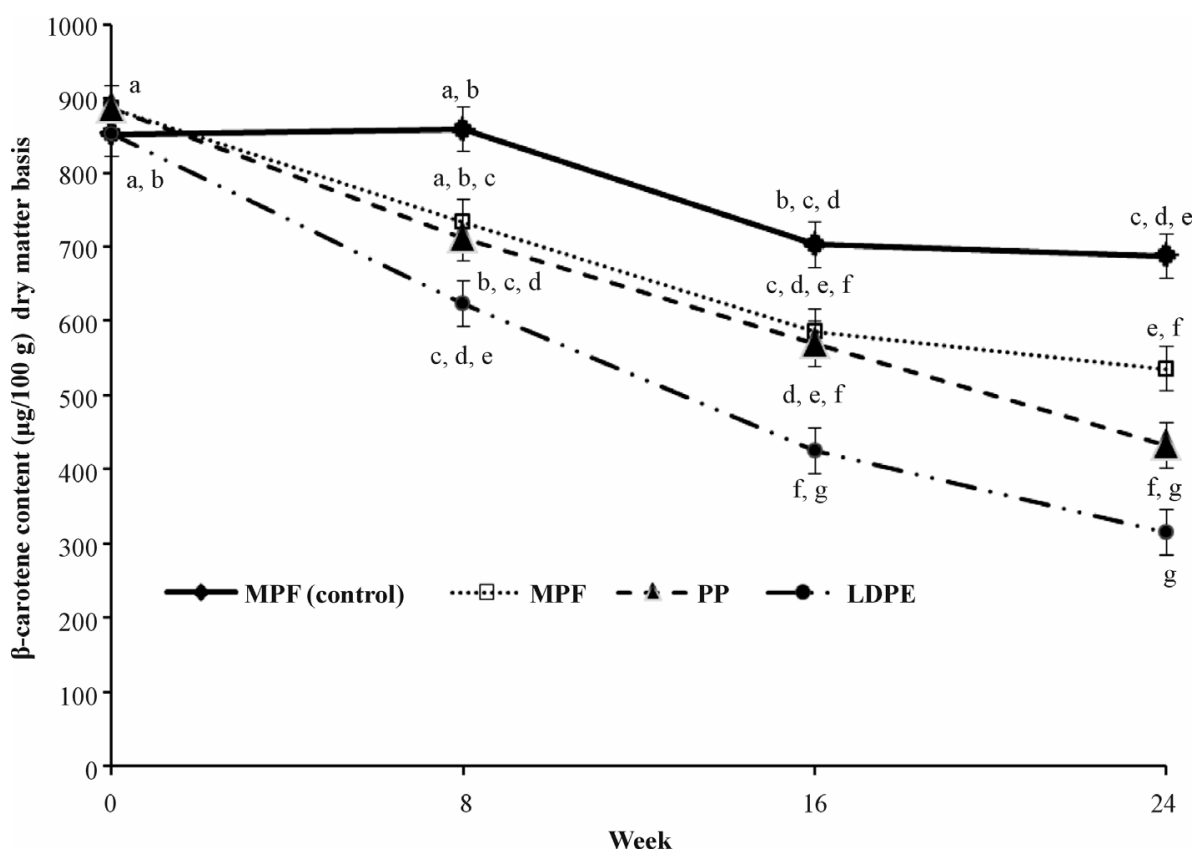

Figure 2. Loss of $\beta$-carotene content in oven-toasted ComFa in different storage containers under simulated tropical temperature and humidity". "Values are least square means \pm standard error of means of three independent sample; Values with the same letter are not significantly different $(P>0.05)$; All treatment levels were stored in an environmental chamber set at $32^{\circ} \mathrm{C}$ and $85 \%$ relative humidity, except MPF (control) that was stored at approximately $3.0^{\circ} \mathrm{C}$ and $95 \%$ relative humidity; MPF: Metallised polyester film; PP: Translucent polypropylene container with low-density polyethylene snap-on lid; LDPE: Transparent low-density polyethylene bag.

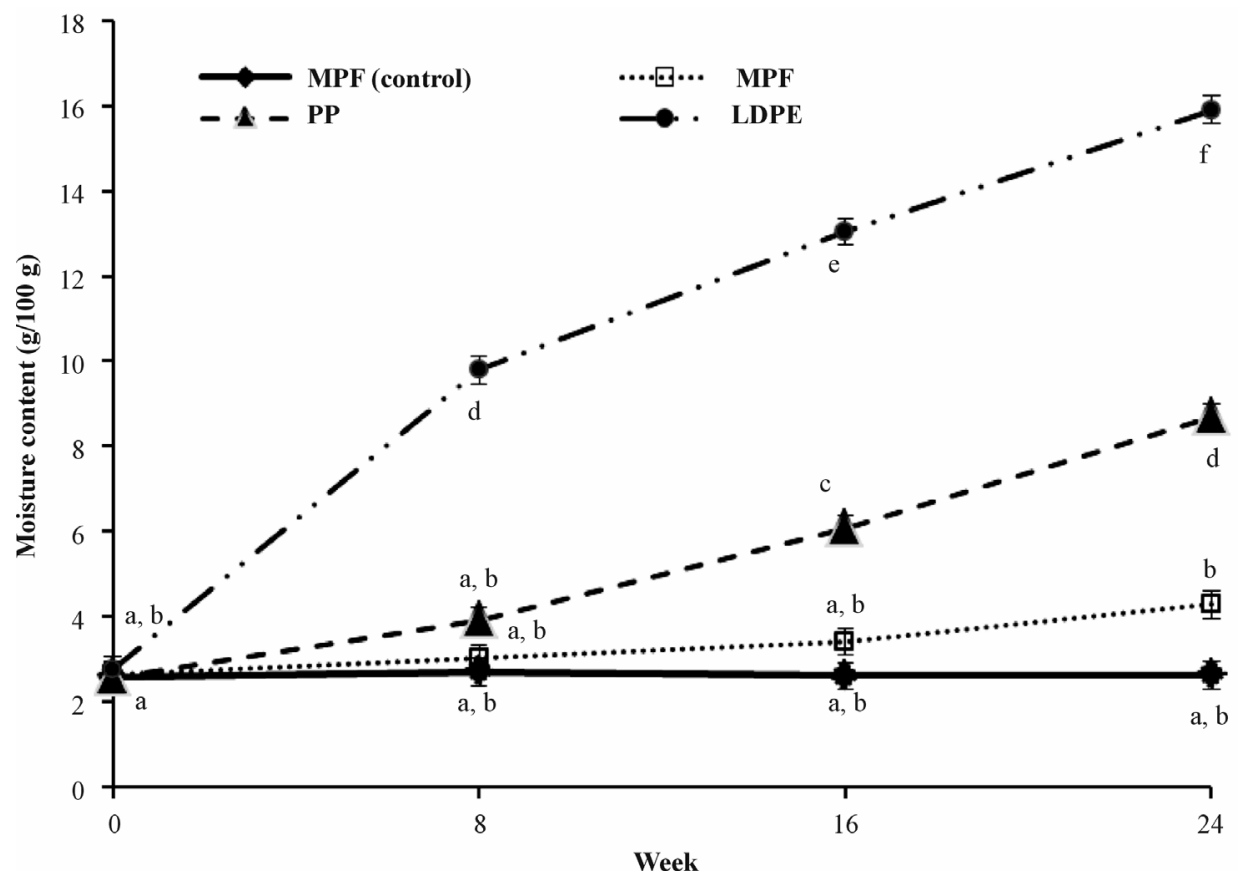

Figure 3. Uptake of moisture by the oven-toasted ComFa in the different storage containers under simulated tropical temperature and humidity ${ }^{\#}$. "Values are least square means \pm standard error of means of three independent sample; Values with the same letter are not significantly different $(P>0.05)$; All treatment levels were stored in an environmental chamber set at $32^{\circ} \mathrm{C}$ and $85 \%$ relative humidity, except MPF (control) that was stored at approximately $3.0^{\circ} \mathrm{C}$ and $95 \%$ relative humidity; MPF: Metallised polyester film; PP: Translucent polypropylene container with low-density polyethylene snap-on lid; LDPE: Transparent low-density polyethylene bag. 
dietary source of vitamin A to support on-going vitamin A supplementation initiatives in low-income countries to reduce vitamin A deficiency occurrence [5,12,15].

The limitations of our storage study include the fixed and extreme simulated tropical conditions (temperature of $32^{\circ} \mathrm{C}$ and relative humidity of $85 \%$ ) in which the storage containers were held, which may not be the ideal situation. Also, the airflow in the environmental chamber was not controlled as it was not equipped with such a function. Additionally, that the cream-fleshed sweetpotato is lower in $\beta$-carotene compared to orange-fleshed sweetpotato [24]. However, within the limits of this stu$\mathrm{dy}$, it has been demonstrated that $\beta$-carotene in sweetpotato-based complementary food is well retained when stored in containers with good moisture barrier at a relatively high temperature and relative humidity.

\section{Conclusion}

The $\beta$-carotene in the sweetpotato-based formulation is fairly stable when stored in containers with good moisture barrier under tropical temperature $\left(32^{\circ} \mathrm{C}\right)$ and relative humidity $(85 \%)$. Thus, the sweetpotato-based formulation could be a dietary source of vitamin A when stored appropriately.

\section{Acknowledgements}

We are indebted to New Zealand International Aid and Development Agency (NZAID) for the Commonwealth PhD scholarship (2009-2012) awarded to FKA. We acknowledge the Nutricia Research Foundation, the Netherlands for providing funds for this research (Project numbers: 2011-30 \& 2012-E6) and thank Delta Produce Co-op Ltd., Dargaville, New Zealand for providing the sweetpotato. The authors are solely responsible for the content of this manuscript and declare no conflicts of interest, financial or otherwise.

\section{REFERENCES}

[1] World Health Organization, "Global Prevalence of Vitamin A Deficiency in Populations at Risk 1995-2005: WHO Global Database on Vitamin A Deficiency," WHO Press, Geneva, 2009.

[2] M. Gibbs, K. B. Bailey, R. D. Lander, U. Fahmida, L. Perlas, S. Y. Hess, C. U. Loechl, P. Winichagoon and R. S. Gibson, "The Adequacy of Micronutrient Concentrations in Manufactured Complementary Foods from LowIncome Countries," Journal of Food Composition and Analysis, Vol. 24, No. 3, 2011, pp. 418-426. doi:10.1016/j.jfca.2010.07.004

[3] A. Lartey, A. Manu, K. H. Brown, J. M. Peerson and K. G. Dewey, "Vitamin A Status of Ghanaian Breast-Fed Infants 6 - 12 Months Fed Improved Complementary Foods," FASEB Journal, Vol. 12, No. 5, 1998, p. A648.
[4] K. G. Dewey and K. H. Brown, "Update on Technical Issues Concerning Complementary Feeding of Young Children in Developing Countries and Implications for Intervention Programs," Food and Nutrition Bulletin, Vol. 24, Special Issue, 2003, pp. 5-28.

[5] F. K. Amagloh, A. Hardacre, A. N. Mutukumira, J. L. Weber, L. Brough and J. Coad, "A Household-Level Sweet Potato-Based Infant Food to Complement Vitamin A Supplementation Initiatives," Maternal and Child $\mathrm{Nu}$ trition, Vol. 8, No. 4, 2012, pp. 512-521. doi:10.1111/j.1740-8709.2011.00343.x

[6] F. K. Amagloh, A. Hardacre, A. N. Mutukumira, J. L. Weber, L. Brough and J. Coad, "Sweet Potato-Based Complementary Food for Infants in Low-Income Countries," Food and Nutrition Bulletin, Vol. 33, No. 1, 2012, pp. 3-10.

[7] F. K. Amagloh, L. Brough, J. L. Weber, A. N. Mutukumira, A. Hardacre and J. Coad, "Sweetpotato-Based Complementary Food Would Be Less Inhibitory on Mineral Absorption than a Maize-Based Infant Food Assessed by Compositional Analysis," International Journal of Food Sciences and Nutrition, Vol. 63, No. 8, 2012, pp. 957-963. doi:10.3109/09637486.2012.687368

[8] F. K. Amagloh, A. N. Mutukumira, L. Brough, J. L. Weber, A. Hardacre and J. Coad, "Carbohydrate Composition, Viscosity, Solubility, and Sensory Acceptance of Sweetpotato- and Maize-Based Complementary Foods," Food and Nutrition Research, Vol. 57, 2013, p. 18717. doi:10.3402/fnr.v57i0.18717

[9] W. Adenuga, "Nutritional and Sensory Profiles of Sweet Potato Based Infant Weaning Food Fortified with Cowpea and Peanut," Journal of Food Technology, Vol. 8, No. 5, 2010, pp. 223-228. doi:10.3923/jftech.2010.223.228

[10] P. I. Akubor, "Evaluation of Physico-Chemical and Sensory Qualities of African Breadfruit and Sweet Potato Based Supplementary Foods," Journal of Food Science and Technology-Mysore, Vol. 42, No. 4, 2005, pp. 292296.

[11] O. S. Ijarotimi and F. Ashipa, "Evaluation of Nutritional Composition, Sensory and Physical Property of Home Processed Weaning Food Based on Low Cost Locally Available Food Materials," Nutrition and Food Science, Vol. 36, No. 1, 2006, pp. 6-17. doi:10.1108/00346650610642142

[12] A. M. Nandutu and N. K. Howell, "Nutritional and Rheological Properties of Sweet Potato Based Infant Food and Its Preservation Using Antioxidants," African Journal of Food, Agriculture, Nutrition \& Development, Vol. 9, No. 4, 2009, pp. 1076-1090.

[13] S. H. Khan, M. S. Butt, F. M. Anjum and A. Sameen, "Quality Evaluation of Rice Bran Protein Isolate-Based Weaning Food for Preschoolers," International Journal of Food Sciences and Nutrition, Vol. 62, No. 3, 2011, pp. 280-288. doi:10.3109/09637486.2010.529802

[14] N. Espinola, H. Creed-Kanashiro, M. E. Ugaz, M. van Hal and G. Scott, "Development of a Sweetpotato-Based Instant Weaning Food for Poorly Nourished Children Six Months to Three Years Old," CIP Program Report 1997- 
98, Vol. 98, Lima, 1997.

[15] M. Omwamba, J. N. Nanua and P. L. Shalo, "Utilization of Orange-Fleshed Sweet Potato Flour in Development of a Suitable Flour Blend for Complementary Infant Food," Egerton Journal of Science and Technology, Vol. 7, 2007. http://journal.egerton.ac.ke/index.php/ejt/article/view/34/ 25

[16] A. Chattopadhyay, I. Chakraborty, P. R. Kumar, M. K. Nanda and H. Sen, "Uncontrolled Storage Behaviour of Sweet Potato (Ipomoea batatas L. Lam)," Journal of Food Science and Technology-Mysore, Vol. 43, No. 1, 2006, pp. 41-45.

[17] Q. Van Oirschot, T. Ngendello, E. Rwiza, R. Amour, K. Tomlins, D. Rees and A. Westby, "The Potential for Storage of Fresh Sweetpotato under Tropical Conditions: Evaluation of Physiological Changes and Quality Aspects," Tropical Root and Tuber Crops, Opportunities for Poverty Alleviation and Sustainable Livelihoods in Developing Countries: Proceedings of the 13th Triennial Symposium of the International Society for Tropical Root Crops, International Society for Tropical Root Crops Arusha, Tanzania, 2007, pp. 423-434.

[18] A. Bechoff, A. Westby, C. Owori, G. Menya, C. Dhuique-Mayer, D. Dufour and K. Tomlins, "Effect of Drying and Storage on the Degradation of Total Carotenoids in orange-Fleshed Sweetpotato Cultivars," Journal of the Science of Food and Agriculture, Vol. 90, No. 4, 2010, pp. 622-629.

[19] R. H. Macedo, P. G. B. de Carvalho, D. A. Leastro, N. S. Alves, J. B. C. Da Silva, M. Nutti and J. L. V. Carvalho,

\section{Abbreviations and Acronyms}

LDPE: Transparent low-density polyethylene bag containing formulation stored at $32^{\circ} \mathrm{C}$ and $85 \%$ relative humidity.

MPF: Metallised polyester film containing formulation stored at $32^{\circ} \mathrm{C}$ and $85 \%$ relative humidity.
"Carotenoid Retention in Sweet Potato Flour," Poster Presentation, 12-15 May 2009.

[20] Climatetemp.info, "Ghana Climate Guide to the Average Weather \& Temperatures with Graphs Elucidating Sunshine and Rainfall Data \& Information about Wind Speeds \& Humidity," 2011. http://www.climatetemp.info/ghana/

[21] Minitab, "Technical Support Document: Analyzing a Repeated Measures Design in Minitab," Knowledgebase ID 2011, Vol. 2012, Minitab Inc., 2012. http://www.minitab.com/support/answers/answer.aspx?ID $=2011$

[22] Minitab, “Technical Support Document: Multiple Comparison Methods," Knowledgebase ID 2011, Vol. 2012, Minitab Inc., 2012.

http://www.minitab.com/support/answers/answer.aspx?ID $=2011$

[23] F. K. Amagloh, J. L. Weber, L. Brough, A. Hardacre, A. N. Mutukumira and J. Coad, "Complementary Food Blends and Malnutrition among Infants in Ghana-A Review and a Proposed Solution," Scientific Research and Essays, Vol. 7, No. 9, 2012, pp. 972-988.

[24] B. J. Burri, "Evaluating Sweet Potato as an Intervention Food to Prevent Vitamin A Deficiency," Comprehensive Reviews in Food Science and Food Safety, Vol. 10, No. 2, 2011, pp. 118-130. doi:10.1111/j.1541-4337.2010.00146.x

MPF: (Control) metallised polyester film containing formulation stored at $3.0^{\circ} \mathrm{C}$ and $95 \%$ relative humidity.

PP: Translucent polypropylene container with low-density polyethylene snap-on lid containing formulation stored at $32^{\circ} \mathrm{C}$ and $85 \%$ relative humidity. 